\title{
Numerical simulation of particle air dispersion around the landfill
}

\author{
N. Samec, M. Hriberšek \& J. Ravnik \\ Faculty of Mechanical Engineering, University of Maribor, Slovenia
}

\begin{abstract}
Paper presents numerical simulation of particles dispersion, lifting from a gypsum landfill under different weather conditions. Simulations consist of two parts: simulation of a long term impact of the particles on the surrounding area, performed by implementation of the Gauss dispersion model based computer code, and second, a CFD based simulation for assessing the flow and mass concentration fields in the vicinity of the landfill for several pre-selected flow cases. The GIS based topography is used for creating computational domain, and the ISC3 software for Gauss dispersion and the CFX5 software for CFD model are implemented. The results of both computational approaches are presented and compared. In the conclusions, a relation of the simulation results with existing environmental pollution levels is made.
\end{abstract}

Keywords: gypsum particles, gypsum landfill, Gauss dispersion model, computational fluid dynamics, wind induced particle transport.

\section{Introduction}

Dust clouds are one of the important environmental risks, especially, when they originate from the artificially made landfills of hazardous material. Since particles, forming dust, are generally very small, they are easily lifted from the landfill and transported into the surroundings. The precondition for lift off must be an adequate velocity field in the vicinity of the landfill surface. In the long term, the most important source of strong velocity field near the surface are winds, therefore position of a landfill must always be weighted by the wind rose, valid for the area under consideration.

In the case of the present study, the landfill under consideration was an existing wet landfill of gypsum. Gypsum landfills are frequently presenting 
environmental risks, especially when gypsum is product of gas cleaning technology [1]. A wet landfill does not present any important environmental risk in terms of dust clouds; however, it does present a technical problem due to low landfill space efficiency. In order to increase the overall mass of deposited gypsum in the landfill, techniques of dry deposition have to be implemented.

Since the impact of the reconstruction on the environment can be experimentally verified only after the reconstruction is finished, a modelling approach to prediction of environmental hazards has to be taken [2]. In order to minimize the impact of the dry gypsum landfill on its surroundings, an extensive experimental and numerical study was carried out. The experimental part was used for determination of mass fluxes from the model landfill surface and for characterisation of basic particle properties. The experimental findings were used in prescribing boundary and initial conditions for numerical simulations of dust propagation.

The main goal of investigations, presented in the paper, was to develop numerical models, which would be able to predict the impact of the gypsum landfill on its environment in terms of solid particles dispersion into the atmosphere. Additionally, during the process, several monitoring stations will be set up, what will later allow a comparison of computed results with results under realistic environmental conditions, and the position of the stations will be determined based on the results of numerical simulations.

\section{Particle characteristics}

The data on structure and size distribution of gypsum particles is one of the most important physical parameters, needed in setting up the correct physical model for numerical simulation. The data was determined for different compositions of the wrung out and build in gypsum. The main cases were the summer composition, consisting of 1 to 1 ratio of both, the winter composition, consisting of fresh gypsum only, and the deposited (wet) gypsum only.

In all cases the test samples of gypsum were prepared by simulating the wringing out the gypsum, as will be performed on the landfill. The simulation was carried out on a laboratory vacuum filter device, able to produce samples with liquid content $<30 \%$. The samples were then analysed using the Mastersizer 2000 (Mavern Instruments Ltd.) measuring device for the size distribution of particles, and additionally investigated under optical and electron microscope for the shape characterisation of particles.

The average density of particles, dried at $45^{\circ} \mathrm{C}$ and $0,9 \%$ wet, for four different samples, was $2.39 \mathrm{~g} / \mathrm{cm}^{3}$, which is close to the nominal density of gypsum, i.e. density of $\mathrm{CaSO}_{4} \times 2 \mathrm{H}_{2} \mathrm{O}=2.317 \mathrm{~g} / \mathrm{cm}^{3}$.

The shape of the dried particles is presented in Fig.1, with a close-up of a typical sample. It can be concluded, that the general shape is a cylindrical and the ratio of the length to diameter is approximately 10 . This data was later used in selecting an adequate empirical correlation for drag coefficient for a particle.

In order to account for the effect of particles of different sizes, the size spectrum was divided into nine size classes, presented in Table 1. 


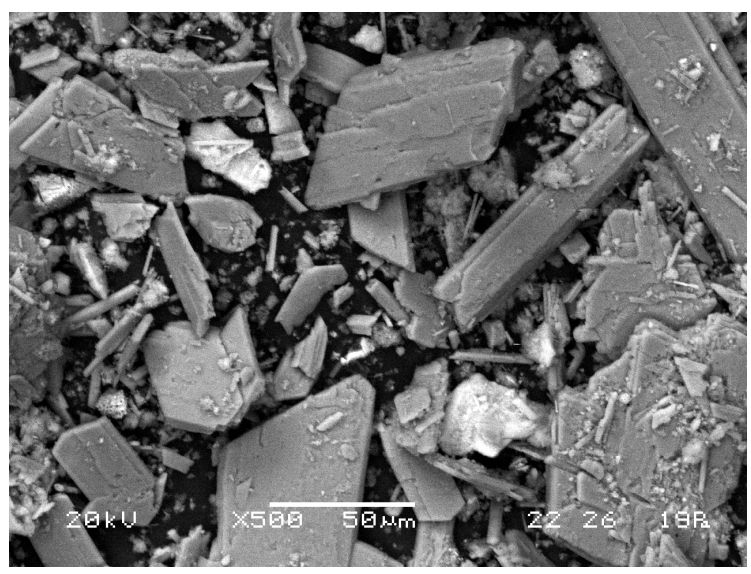

Figure 1: $\quad$ Dry gypsum particles under the electron microscope.

Table 1: $\quad$ Size distribution of gypsum particles after the mechanical loading experiment.

\begin{tabular}{|c|c|}
\hline $\begin{array}{c}\text { Particle equivalent } \\
\text { diameter [um] }\end{array}$ & Mass fraction [\%] \\
\hline 5 & 38.7 \\
\hline 15 & 16.5 \\
\hline 25 & 7.5 \\
\hline 35 & 6.6 \\
\hline 45 & 3.8 \\
\hline 60 & 6.0 \\
\hline 85 & 5.8 \\
\hline 150 & 9.6 \\
\hline 320 & 5.5 \\
\hline
\end{tabular}

\section{Numerical models}

Numerical models form the core of modern engineering simulation tools. They range from complex models, incorporating governing physical phenomena of fluid flow and mass transfer on differential level, to simplified models, based on lumped parameter approach and with simplified solutions for fluid flow and mass transfer. In the case of modelling of dust clouds and deposition of particles complex models produce detailed spatial results, but can become computationally too demanding for simulating large time spans. The latter is the domain of simplified models, which however lack of spatial resolution. 
In the present work we performed numerical simulation by using both types of numerical models, specifically:

1. Gauss dispersion model, incorporated in the numerical code ISCISCST3 [3-5],

2. Computational Fluid Dynamics model (CFD), in our case in the form of the numerical code ANSYS-CFX [6].

There exist several other models, which were already successfully applied in environmental modelling [7,8], especially Lagrange models, incorporating lumped parameter approach with control volume movement according to predetermined flow field [9].

Regardless of the numerical model used, the results of numerical simulations always depend strongly on input data, in our case:

1. Particle characteristics: size (equivalent diameter), size distribution, specific weight of wet and dry particles, characteristic shape and corresponding coefficient of dynamic drag.

2. Mass flux of particles, entering the flow domain as a consequence of wind interaction with landfill surface.

3. Direction and magnitude of winds in the surroundings of the landfill, mostly on several years average basis.

\section{Computational domain, boundary and initial conditions}

\subsection{The Gaussian plume model}

The modelling was done using the ISCST3 model, developed by the EPA [3, 4]. The model encompassed 100 square kilometres abound the gypsum landfill. Northeastern corner was defined in Gauss-Krueger coordinate system at $(5531500 \mathrm{~m}, 5126000 \mathrm{~m})$ and the Southwestern corner at $(5521092 \mathrm{~m}, 5115633 \mathrm{~m})$. Thus the height of the model is $10367 \mathrm{~m}$ and the width $10407 \mathrm{~m}$.

The model requires data on the landfill as well. We chose:

- Size of the open part of the landfill: $25 \times 10 \mathrm{~m}$,

- Landfill volume: $250 \mathrm{~m}^{3}$

- Landfill surface: $250 \mathrm{~m}^{2}$

- $\quad$ Particles are lifted from the bottom of the landfill.

- Coefficients describing rinsing of gypsum in rain and snow were both set to $0.0001 \mathrm{hr} / \mathrm{mm} \mathrm{s}$.

The meteorological data was gathered from the stations for the period between 1.5.2003 and 19.11.2005. The first is located at the landfill measuring the temperature, precipitation and wind direction and velocity. The second is located in the nearby town of Celje, where data on relative humidity, cloud cover, cloud height, sun radiation and air pressure was gathered. The data was written in the SAMSON (Solar and Meteorological Surface Observational Network) format and a RAMMET [5] meteorological pre-processor was used to prepare data for our model. RAMMET requires also additional terrain data, given in Table 2. The AERMIX model [5] was used to estimate the mixing heights. 
Table 2: $\quad$ Terrain properties for meteorological data.

\begin{tabular}{|l|l|l|}
\hline Data & Unit & Value \\
\hline Anemometer height & $\mathrm{M}$ & 2 \\
\hline Minimum Monin-Obukhov length & $\mathrm{m}$ & 2 \\
\hline Surface roughness length (measurement site) & $\mathrm{m}$ & 0.1 \\
\hline Surface roughness length (application site) & $\mathrm{m}$ & 0.1 \\
\hline Noon-Time Albedo & & 0.18 \\
\hline Bowen ratio & & 0.8 \\
\hline Anthropogenic Heat Flux & $\mathrm{W} / \mathrm{m}^{2}$ & 43 \\
\hline Fraction of net radiation absorbed at the ground & & 0.15 \\
\hline
\end{tabular}

\subsection{The CFD model}

The area under consideration encompassed $10.5 \mathrm{~km}$ times $10.5 \mathrm{~km}$ with the landfill located in the centre. Digital model of heights was used to model the terrain. The upper boundary of the domain was flat, set $2612 \mathrm{~m}$ above the lower point in the terrain. The side walls of the domain were vertical. Based on the geometrical model a computational grid was set up having 434,000 elements. The gird is condensed around the landfill and shown in Figure 2. Figure 3 shows the boundary conditions. Inflow of air was prescribed on two vertical walls and an outflow on the other two.

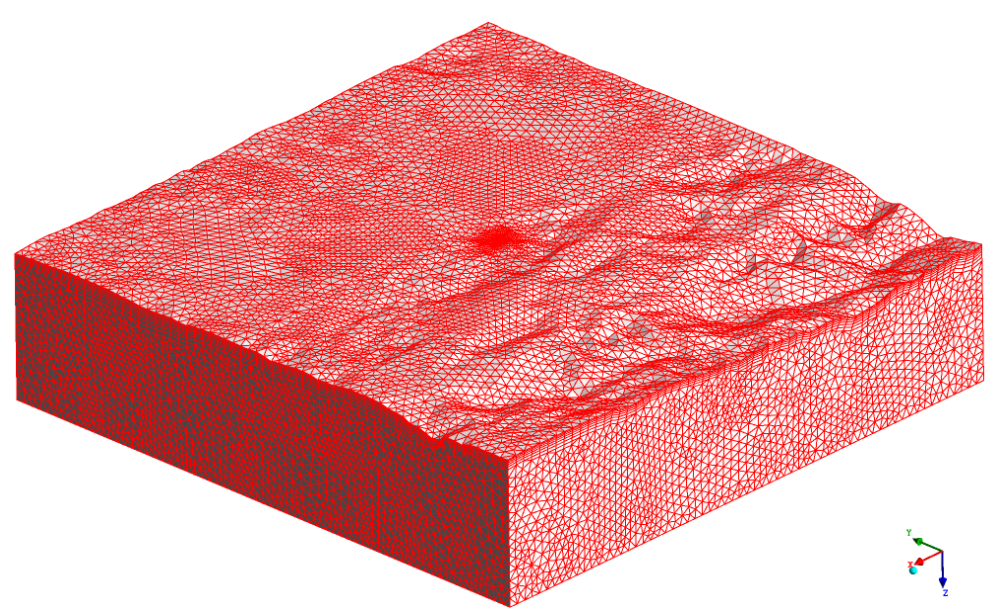

Figure 2: $\quad$ The grid used in the CFD model (view from the bottom). 


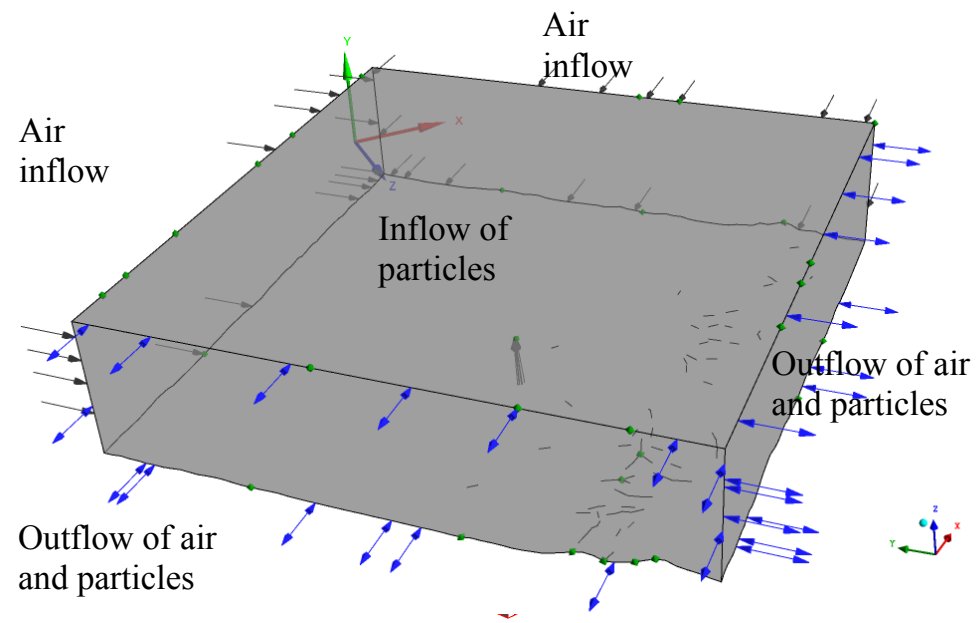

Figure 3: The boundary conditions of the CFD model.

\subsection{Determination of inflow particle mass flux}

An experiment was set up to determine the flux of particles leaving the landfill. We prepared a flat surface of dry gypsum. A heavy roller drove over the surface a few times to crumble the gypsum. An artificial wind of $1.0 \mathrm{~m} / \mathrm{s}-1.2 \mathrm{~m} / \mathrm{s}$ was directed over the surface. Other conditions were constant (temperature, humidity). The results showed that only particles with sizes lower than 50 microns were lifted. Also, we noticed that the emission index rises substantially when gypsum is crumbled by heavy machinery. The emission index of installed gypsum is more than an order of magnitude smaller. The worst case scenario thus happens in dry conditions on the open part of the landfill, when heavy machinery crumbles the gypsum surface.

\section{Results of numerical simulations}

\subsection{Gaussian plume model}

The Gaussian plume model ISCST3 was run with meteorological data between May 2003 and November 2005. Gypsum with density $2210 \mathrm{~kg} / \mathrm{m}^{3}$ was chosen. Emission index of installed gypsum $0.0021 \mathrm{~g} / \mathrm{s} / \mathrm{m}^{2}$ and of mixed gypsum 0.0026 $\mathrm{g} / \mathrm{s} / \mathrm{m}^{2}$ was chosen. The gypsum diameter/mass fractions distribution used in the model is listed in Table 1.

Figure 4 shows isolines of constant gypsum concentration in air, by showing the second worst daily averaged value in each individual node in the period May 2003 - November 2005. We observe that the concentration decreases almost in concentric circles around the landfill. The predominant South-Eastern wind direction is evident from the isolines of low concentration, i.e. $10-15 \mu \mathrm{g} / \mathrm{m}^{3}$. 


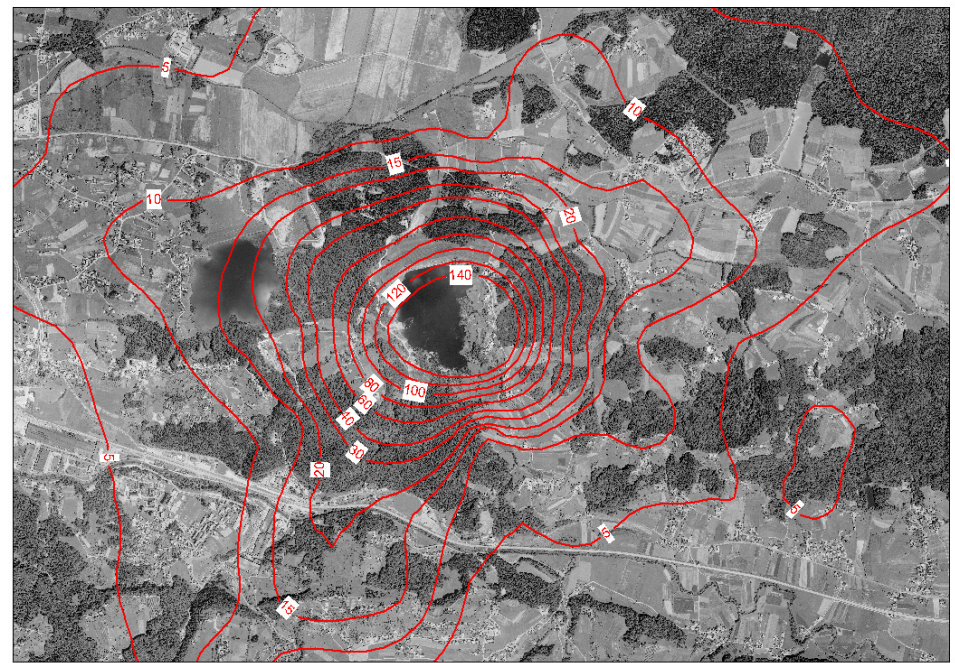

Figure 4: Isolines of concentration of gypsum in air, $\left[\mu \mathrm{g} / \mathrm{m}^{3}\right]$, second highest value, 24 hour averages, density $2210 \mathrm{~kg} / \mathrm{m}^{3}$, emission flux: $0.0021 \mathrm{~g} / \mathrm{s} / \mathrm{m}^{2}$.

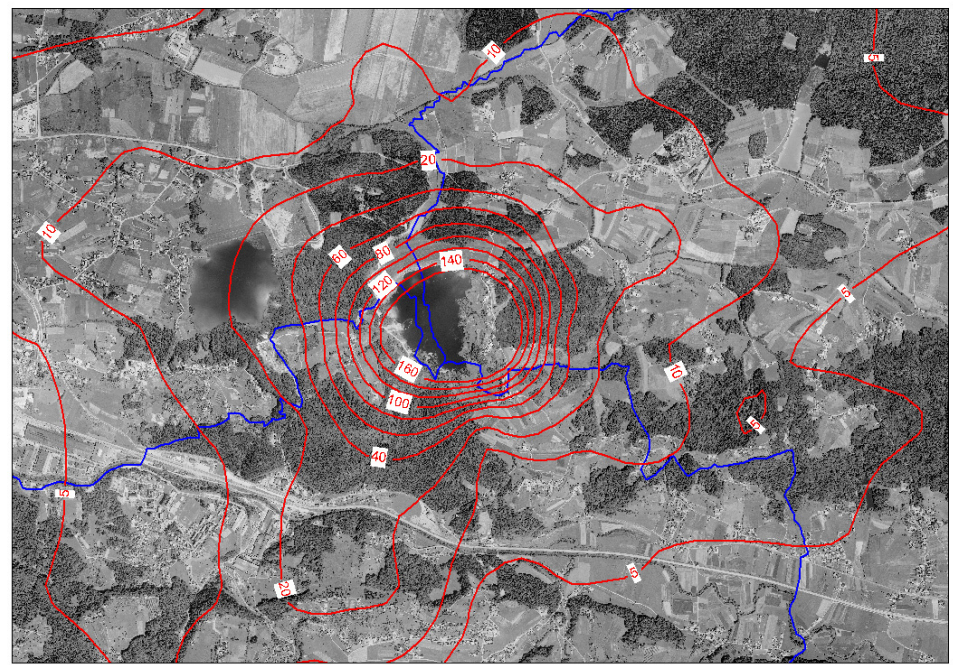

Figure 5: Isolines of concentration of gypsum in air, $\left[\mu \mathrm{g} / \mathrm{m}^{3}\right]$, second highest value, 24 hour averages, density $2210 \mathrm{~kg} / \mathrm{m}^{3}$, emission flux: $0.0026 \mathrm{~g} / \mathrm{s} / \mathrm{m}^{2}$. 
Figure 5 shows the results of simulation of mixed gypsum, where the measures emission flux was $0.0026 \mathrm{~g} / \mathrm{s} / \mathrm{m}^{2}$. The results are almost identical to those obtained for installed gypsum.

We may conclude, that in the worst case scenario, we may expect 1 day in two and a half years when $750 \mathrm{~m}$ away from the centre of the landfill the gypsum concentration in air will reach about $40 \mu \mathrm{g} / \mathrm{m}^{3}$ and about $0.15 \mathrm{~g} / \mathrm{m}^{2}$ of gypsum will be deposited on this day.

\subsection{CFD model}

We analysed dry non-stick gypsum with density of $2210 \mathrm{~kg} / \mathrm{m}^{3}$. We analysed three dominant wind directions;. For the $45^{\circ}$ North-Eastern wind, Figures 6-8 show isosurfaces of instantaneous concentration of gypsum with $4.5 \mu \mathrm{m}$ diameter for different values of concentrations.

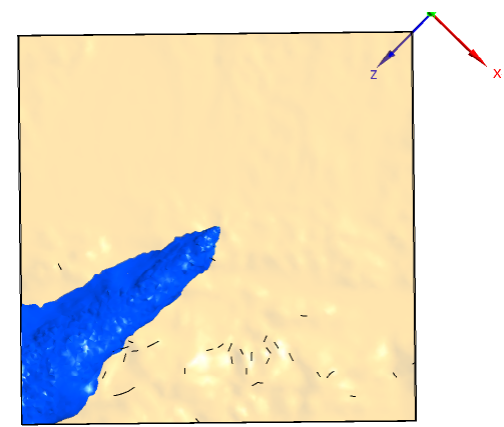

(a)

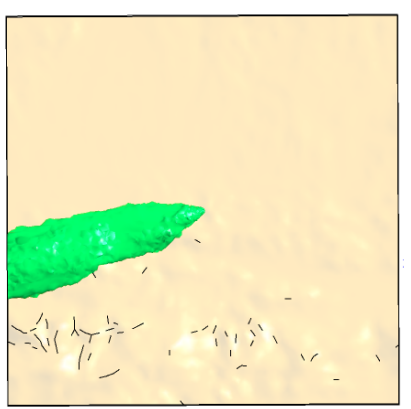

(b)

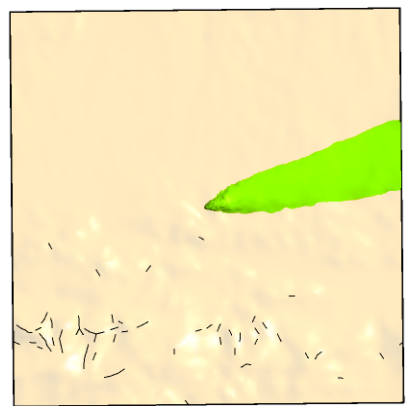

(c)

Figure 6: Isosurface of constant concentration $1.0 \times 10^{-5} \mu \mathrm{g} / \mathrm{m}^{3}$, for particles with diameter of $4.5 \mu \mathrm{m}$. Density of gypsum $2210 \mathrm{~kg} / \mathrm{m}^{3}$, wind direction $45^{\circ} \mathrm{NE}, 67.5^{\circ} \mathrm{ENE}$ and $247.5^{\circ} \mathrm{WSW}$, (a) to (c).

It is evident from the results that the hills in the South greatly affect the concentration and deposition fields. Although their presence was included in the Gaussian plume model as well, the CFD model shows their influence better. The high concentration of gypsum $4.5 \mu \mathrm{m}$ diameter particles, $1.0 \times 10^{-3} \mu \mathrm{g} / \mathrm{m}^{3}$, is shown in Figure 7 . It reveals that only a narrow area directly in the direction of 


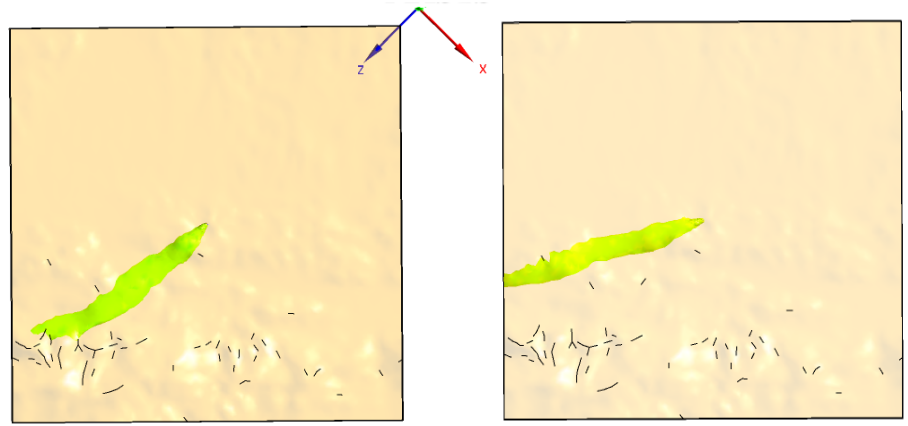

(a)

(b)

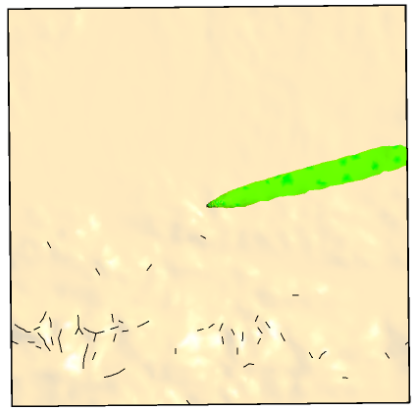

(c)

Figure 7: Isosurface of constant concentration $1.0 \times 10^{-3} \mu \mathrm{g} / \mathrm{m}^{3}$ for particles with diameter of $4.5 \mu \mathrm{m}$. Density of gypsum $2210 \mathrm{~kg} / \mathrm{m}^{3}$, wind direction $45^{\circ} \mathrm{NE}, 67.5^{\circ} \mathrm{ENE}$ and $247.5^{\circ} \mathrm{WSW}$, (a) to (c).

the wind will have high concentration of gypsum in the air. Diffusion in directions perpendicular to the dominant wind direction is relatively small, which can be seen in the plots of isosurfaces of small concentration in Figure 6.

Maximal deposition rates for the computed test cases were:

- Wind $45^{\circ} \mathrm{NE}: 6,386 \times 10^{-3} \mu \mathrm{g} / \mathrm{m}^{2} \mathrm{~s}$,

- Wind $67.5^{\circ}$ ENE: $7,55 \times 10 \times 10^{-3} \mu \mathrm{g} / \mathrm{m}^{2} \mathrm{~s}$,

- Wind $247.5^{\circ} \mathrm{WSW}: 7,099 \times 10^{-3} \mu \mathrm{g} / \mathrm{m}^{2} \mathrm{~s}$.

which qualitatively corresponds well with the results of Gaussian model.

A quantitative comparison is directly not possible, as the CFD model gives instantaneous values of concentration fields [10], and their integration in time would not be comparable with results of Gaussian models, which implement varying meteorological conditions.

The simulation confirmed our assumption that the wind direction is the main factor influencing the transport and distribution of gypsum particles. Concentrations of gypsum in the air were found to be relatively small. On average it was found to be approximately $0.12 \mu \mathrm{g} / \mathrm{m}^{3}$, while the minimal concentrations were $2.3 \times 10^{-6} \mu \mathrm{g} / \mathrm{m}^{3}$. The highest levels were found in the 


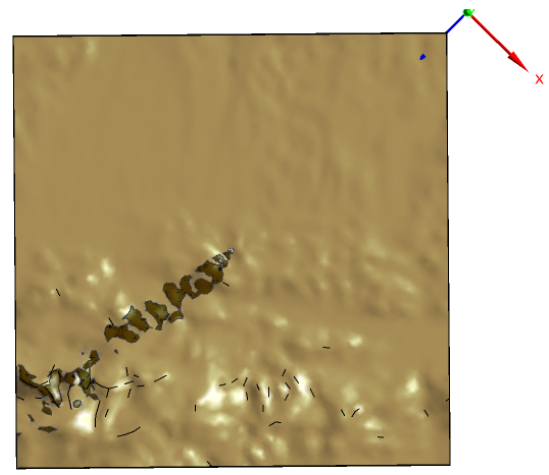

(a)

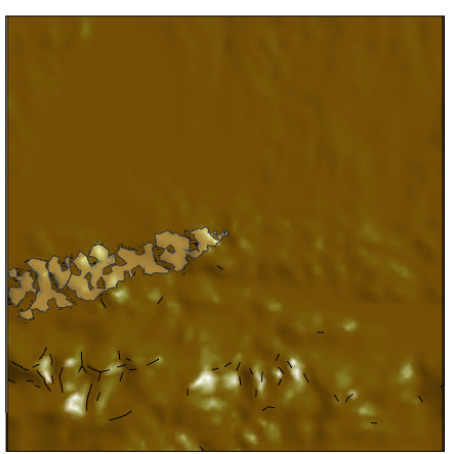

(b)

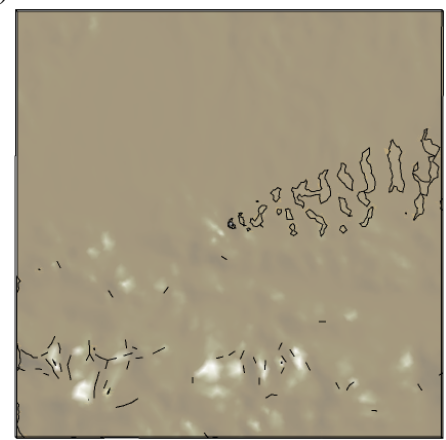

(c)

Figure 8: Deposition of gypsum with diameter of $4,5 \mu \mathrm{m}$. Wind direction $45^{\circ} \mathrm{NE}, 67.5^{\circ} \mathrm{ENE}$ and $247.5^{\circ} \mathrm{WSW}$, (a) to (c).

immediate surrounding of the landfill. They diminished quickly as we move away from the landfill. Particles of smaller diameter showed better mobility and were found the farthest away from the landfill.

\section{Conclusions}

In the process of transformation of a wet gypsum landfill into a dry one environmental hazards of the process have to be evaluated in order to adapt the transformation procedures. As one of the hazards is dusting of dry particles due to strong winds, the goal of the presented research work was to find, how dangerous this transformation process would be and how it will affect the surroundings of the landfill. As the meteorological influences are the most important in this case, computational study was performed.

In general, the Gaussian models do give a strong indication on the average concentrations of the particles in the air and their deposition, however, they do lack of spatial resolution. In this sense, the combination with CFD based models can give a deeper insight into the flow field and corresponding particle 
concentration fields in the directions, in which the critical contamination of the environment is to be expected. The computational results will serve as a basis for long term monitoring of spreading and deposition of particles in the surroundings of the gypsum landfill.

\section{Acknowledgements}

The authors thank Mr Kolarič and Mrs Podgoršek-Kovač for their work in the field of CFD modelling and characterisation of particle properties.

\section{References}

[1] Plaza, C., Xu, Q., Townsend, T., Bitton, G., Booth, M. Evaluation of alternative landfill cover soils for attenuating hydrogen sulfide from construction and demolition (C\&D) debris landfills. Journal of Environmental Management, Volume 84, Issue 3, Pages 314-322, 2007.

[2] Nazaroff, W., W., Alvarez-Cohen, L.: Environmental engineering science. John Wiley and Sons, 2001.

[3] U. S. Environmental Protection Agency: User's guide for the Industrial Source Complex (ISC3) Dispersion Models - Volume 1 (Revised). EPA454/B-95-003a. Office of Air Quality Planning and Standards, Research Triangle Park, NC, 1995.

[4] U. S. Environmental Protection Agency: User's guide for the Industrial Source Complex (ISC3) Dispersion Models - Volume II - Description of model algorithms. EPA-454/B-95-003b. Office of Air Quality Planning and Standards, Research Triangle Park, NC, 1995.

[5] ISC-AERMOD View, Interface for the U.S. EPA ISC and AERMOD Models, Lakes Environmental, 2006.

[6] Ansys-CFX 5.7, AEA Technology, 2004.

[7] N.S. Holmes and L. Morawska: A review of dispersion modelling and its application to the dispersion of particles: An overview of different dispersion models available. Atmospheric Environment, Volume 40, Issue 30, pp. 5902-5928, September 2006,

[8] VDI 3783 Bl. 12 Entwurf. Umweltmeteorologie. Physikalische Modellierung von Stroemungs- uns Ausbreitungsvorgaengen in der atmosphaerischen Grenzschicht. Berlin: Beuth Verlag, 1999.

[9] Steven R. Hanna, Olav R. Hansen, Seshu Dharmavaram: FLACS CFD air quality model performance evaluation with Kit Fox, MUST, Prairie Grass, and EMU observations. Atmospheric Environment, Volume 38, Issue 28, pp. 4675-4687, September 2004.

[10] Kolarič, D.: Numerical simulation of spreading of solid particles from two dimensional source (in slovene). Master of science thesis, Faculty of Mechanical Engineering, Maribor, Slovenia, 2007. 